\title{
Laboratory and In Situ Simulation Tests of the Excavation Damaged Zone Around Galleries in Opalinus Clay
}

\author{
Vincent Labiouse • Tim Vietor
}

Received: 5 February 2013/Accepted: 12 February 2013/Published online: 5 March 2013

(C) Springer-Verlag Wien 2013

\begin{abstract}
In the context of nuclear waste disposal in clay formations, laboratory and in situ simulation experiments were performed to study at reduced scale the excavation damaged zone (EDZ) around tunnels in the indurated Opalinus Clay at Mont Terri, Switzerland. In the laboratory, thick-walled hollow cylindrical specimens were subjected to a mechanical unloading mimicking a gallery excavation. In samples cored parallel to bedding, cracks sub-parallel to the bedding planes open and lead to a buckling failure in two regions that extend from the borehole in the direction normal to bedding. The behaviour is clearly anisotropic. On the other hand, in experiments performed on specimens cored perpendicular to bedding, there is no indication of failure around the hole and the response of the hollow cylinder sample is mainly isotropic. The in situ experiment at Mont Terri which consisted in the overcoring of a resin-injected borehole that follows the bedding strike of the Opalinus Clay showed a striking similarity between the induced damaged zone and the fracture pattern observed in the hollow cylinder tests on samples cored parallel to bedding and such a bedding controlled "Excavation" Damaged Zone is as well
\end{abstract}

TIMODAZ project co-funded by the European Commission and performed as part of the sixth EURATOM Framework Programme for nuclear research and training activities (2002-2006) under contract FI6W-CT-2007-036449.

V. Labiouse $(\square)$

Rock Mechanics Laboratory (LMR), Ecole Polytechnique

Fédérale de Lausanne (EPFL), Lausanne, Switzerland

e-mail:Vincent.labiouse@epfl.ch

URL: http://lmr.epfl.ch/

T. Vietor

National Cooperative for the Disposal of Radioactive Waste

(NAGRA), Wettingen, Switzerland consistent with the distinct fracture patterns observed at Mont Terri depending on the orientation of holes/galleries with respect to the bedding planes. Interestingly, the damaged zone observed in the hollow cylinder tests on samples cored parallel to bedding and in situ around URL galleries is found to develop in reverse directions in Boom Clay (Mol) and in Opalinus Clay (Mont Terri). This most probably results from different failure mechanisms, i.e. shear failure along conjugated planes in the plastic Boom Clay, but bedding plane splitting and buckling in the indurated Opalinus Clay.

Keywords Hollow cylinder test - In situ simulation test . Excavation damaged zone $\cdot \mathrm{X}$-ray computed tomography · Opalinus Clay $\cdot$ Nuclear waste disposal

\section{Introduction}

In tunnelling engineering, the development of a damaged zone around underground openings is a source of concern because it may lead to collapses during the construction stage and to an additional loading of the final lining. In the context of geological disposal of radioactive waste, another major concern is the potential alteration of flow and radionuclides transport properties in this zone that could affect the long-term safety of a repository. Accordingly, the excavation damaged zone (EDZ) is defined as a zone with hydro-mechanical or geochemical modifications inducing significant changes (i.e. one or more orders of magnitude) in flow and transport properties (Tsang and Bernier 2004). It is distinguished from the excavation disturbed zone (EdZ) where the hydro-mechanical and geochemical modifications are insufficient to induce major changes in flow and transport properties. Within the EdZ, there are no 
negative effects on the long-term safety (Blümling et al. 2007).

In this context, the TIMODAZ project (Thermal Impact on the Damaged Zone Around a Radioactive Waste Disposal in Clay Host Rocks) carried out within the 6th EURATOM Framework Program of the European Community aimed at studying the fracturing and self-sealing processes that develop in the EDZ around disposal galleries for heat emitting radioactive waste and at assessing the impact of a thermal phase on their evolution. Among the three different potential geological formations for deep radioactive waste repositories investigated in the project (i.e. Boom, Opalinus and Callovo-Oxfordian clay formations), this study focuses on the indurated Opalinus Clay of Mont Terri (Switzerland). The Opalinus Clay is a formation of homogenous indurated claystones of Lower Dogger age. The $80-120 \mathrm{~m}$ thick homogenous marine rock formation is considered as a suitable host rock for deep geological repositories of radioactive waste in the northeastern part of Switzerland (Nagra 2002). In those potential site regions the formation is flat lying and the tectonic overprint is only very mild (Nagra 2008).

The international Mont Terri Underground Rock Laboratory (URL) is a collaborative project of 14 partners from eight countries used since 1996 for in situ experiments in the Opalinus Clay (Vietor et al. 2008). The URL galleries branch off a highway tunnel close to the town of Saint Ursanne, Switzerland. The laboratory is located in an anticline of the folded Jura (Switzerland) and therefore the in situ conditions are strongly influenced by the tectonic overprint. According to Martin and Lanyon (2003), stress estimates using various methods indicate a sub-vertical orientation of the largest principal stress with a magnitude of 6.5-7 MPa. The intermediate principal stress is estimated to be in the range of $4 \mathrm{MPa}$, subhorizontal and normal to the bedding strike. The minimum principal stress is sub-horizontal and parallel to the strike of the bedding and the anticline fold axis. The in situ pore water pressure is $2.0 \mathrm{MPa}$. In the URL, the Opalinus Clay dips between $30^{\circ}$ and $55^{\circ}$ to $\mathrm{N} 155 \mathrm{E}$ and has an apparent thickness of approximately $160 \mathrm{~m}$.

The current paper deals with rocks from the shaly facies at the Mont Terri rock laboratory. A representative mineralogical composition comprises $66 \%$ clay minerals (range $28-93 \%$ ), $22 \%$ quartz $(10-32 \%), 9 \%$ of carbonates $(4-22 \%), 2 \%$ of feldspars $(1-4 \%)$ and $1 \%$ of pyrite. The rock shows a clear anisotropy in geophysical, hydraulic and mechanical properties (e.g. Popp et al. 2008). The anisotropy results from the bedding parallel preferred orientation of clay minerals at the nano scale and of platy bioclasts (mostly shell fragments) at the micro scale.

The paper first presents laboratory simulation tests performed at the Rock Mechanics Laboratory LMR of the EPFL, Switzerland. Whereas explanations about the testing device and procedure are provided in a companion paper (Labiouse et al. 2013), this paper focuses on the results on Opalinus Clay hollow cylindrical samples cored parallel and perpendicular to bedding. Next, an in situ experiment designed at the Mont Terri URL by the Swiss National Cooperative for the Disposal of Radioactive Waste NAGRA is described and the observed EDZ is commented. Finally, these laboratory and in situ experimental data are compared with in situ observations around galleries and boreholes driven at the Mont Terri URL.

\section{Laboratory Simulation Tests}

\subsection{Description}

The testing device consists of a specially designed triaxial cell with an aluminium body allowing for X-ray computed tomography (XRCT) scans of samples through the cell walls at different stages during testing (Labiouse et al. 2013). Four separate hydraulic circuits and pressure-volume controllers enable an independent control of the confining and drain pressures acting at the outer and inner boundaries of hollow cylindrical specimens.

Laboratory simulation tests aiming at mimicking at reduced scale the construction of galleries at the Mont Terri site were performed on thick-walled hollow cylindrical samples (14 and $86 \mathrm{~mm}$ inner and outer diameters, respectively) prepared by drilling in dry conditions a coaxial central hole in drill cores sampled with a doubletube core barrel (flushing with compressed air) and preserved in vacuum packed plastic films.

Because anisotropic in situ conditions can not be simulated in hollow cylinder tests, it was chosen to perform the experiments with initial conditions close to the mean total and effective stresses at Mont Terri URL. As they are actually pretty close to the in situ conditions at Mol URL in the Boom Clay formation, the initial testing conditions on Boom Clay samples (Labiouse et al. 2013) were kept for the experiments on Opalinus Clay, i.e. total confining pressures of 4.5 MPa and pore water pressure of $2.2 \mathrm{MPa}$.

On the other hand, as the galleries of the Mont Terri URL are mostly lined with shotcrete sprayed on the walls, the support pressure is much lower (in the order of $100-200 \mathrm{kPa}$ ) than the pressure acting on the concrete segments used in the connecting and Praclay galleries at Mol URL (Van Marcke and Bastiaens 2010). For that reason, the mechanical unloading stage that aims at modelling the gallery construction was achieved by decreasing the confining pressure in the central hole from 4.5 to $0.2 \mathrm{MPa}$. 
Figure 1 schematically presents the successive stages of an experiment:

1. Recovery of in situ stress conditions. Preloading of the sample, saturation of the hydraulic circuits and drains, loading up to the in situ stress conditions (total stress of 4.5 $\mathrm{MPa}$ and pore water pressure of $2.2 \mathrm{MPa}$ ) and consolidation for at least 1 month.

2. Mechanical unloading. The confining pressure in the central hole $\sigma_{3}$ int is reduced from 4.5 to $0.2 \mathrm{MPa}$ in 70 min while the outer confining pressure $\sigma_{3 \text { ext }}$ is kept constant at $4.5 \mathrm{MPa}$. This stage aims at inducing a damaged zone around the central hole.

3. Drainage. During this stage, the inner confining and drain pressures are kept constant at, respectively, 0.2 and $0.1 \mathrm{MPa}$ and a redistribution of pore water pressures is occurring in the clay specimen.

4. Thermal loading. On one sample, a heating and cooling cycle was imposed in the central hole to model a thermal loading by the nuclear waste. This was achieved by keeping the inner and outer confining pressures constant and by increasing the temperature of the inner confining fluid.

To study the development and the evolution of the damaged zone induced around the central hole without removing the sample from the testing cell, permeability measurements and X-ray computerized tomography (XRCT) scans were carried out at different steps of the experiments. Because the medical scanner at Lausanne cantonal hospital (CHUV) has a medium resolution (voxel size of $0.215 \mathrm{~mm}$ ) and the displacements undergone by the Opalinus Clay specimens were rather low, it was unfortunately not possible to perform quantitative analyses by means of image processing methods. However, qualitative considerations about the damaged zone developing around the central hole were made by comparing the successive XRCT scans and checked after disassembly of the test by visual inspection of saw-cut sections.
Permeability measurements carried out before and after the mechanical unloading aimed at observing any change in flow properties related to the development of a damaged zone around the central hole. They were performed under radial convergent flows by imposing a constant pressure difference between the outer and inner hydraulic drains, i.e. 100 and $2,100 \mathrm{kPa}$, respectively before and after the mechanical unloading (Fig. 1). Despite the rather short drainage path, due to the extremely low hydraulic conductivity of virgin Opalinus Clay (less than $10^{-12} \mathrm{~m} / \mathrm{s}$ ), a very long time would have been necessary to reach a fully steady state flow in the sample (i.e. several weeks). Consequently, for pragmatic reasons, some permeability measurements were carried out under still transient conditions, after about 7 days of flow. Their accuracy was assessed from the difference in water fluxes entering and leaving the sample. The hydraulic conductivity results presented later are average values for the whole specimen; they include the anisotropic permeability of the virgin clay and its possible change in the damaged zone developing around the central hole. A thorough analysis would need to be undertaken to distinguish the respective contributions.

\subsection{Samples Cored Parallel to Bedding}

An Opalinus Clay sample (No. 12) was prepared in a drill core parallel to the bedding planes and subjected to the three first stages described in the previous section (Fig. 1). X-ray scans were performed before the mechanical unloading and 15 days after it, the inner confining pressure and inner drain pressure being kept constant at, respectively, 200 and $100 \mathrm{kPa}$. Three more X-ray scans were performed after the removal of the sample from the testing cell, one after 8 days in a high-resolution machine (Phoenix at Hannover, Germany) and the others after 170 and 220 days in the medium-resolution medical scanner of the CHUV.

The XRCT scans presented in Fig. 2 were performed at Lausanne cantonal hospital (CHUV). The upper pictures
Fig. 1 Successive stages of the hollow cylinder simulation experiments. Indicative evolution of external cell pressure $\sigma_{3 \mathrm{ext}}$, central hole pressure $\sigma_{3 \text { int }}$, outer drain pressure $u_{\text {ext }}$ and inner drain pressure $u_{\text {int }}$. The time and duration of the stages varied from one test to the other

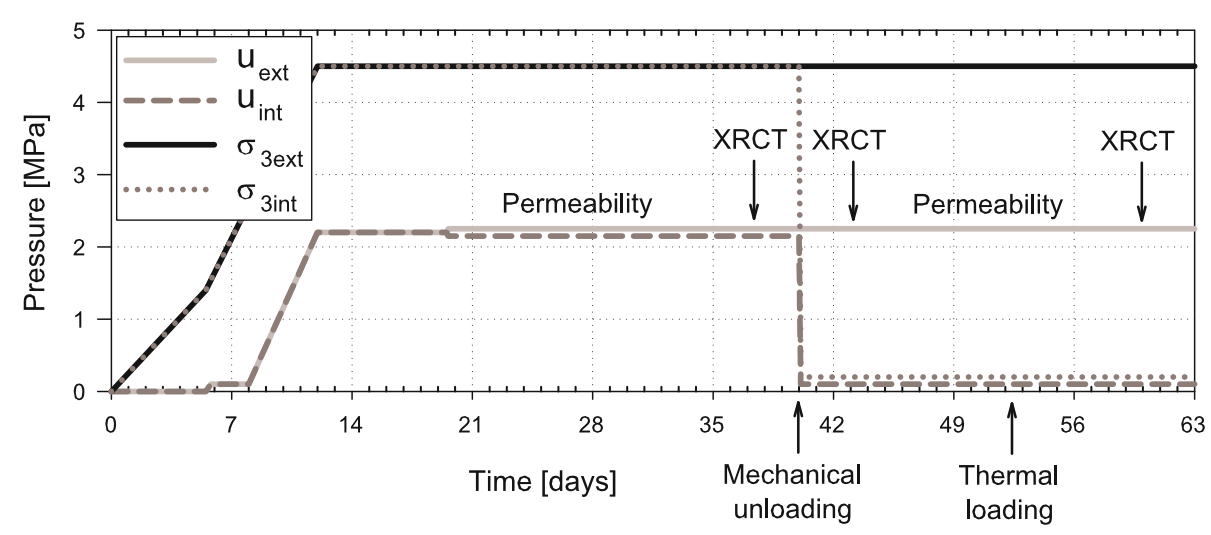


are scans of the sample inside the cell before (left) and after (right) the mechanical unloading. Hardly any change is observed, except a very small oval-shaped deformation of the borehole and a slight decrease in rock density (i.e. darker grey) close to it, which could let think that a damaged zone had been induced by the mechanical unloading. The lower pictures are scans of the same sample carried out 170 and 220 days after its removal from the testing cell (left and right pictures, respectively). A further ovalisation of the central hole is noticed and fractures are now discernible close to the wall in a zone extending perpendicularly to the bedding planes.

Eight days after the removal of the sample from the testing cell, a high-resolution XRCT of the central part of the Opalinus clay sample $\mathrm{N}^{\circ} 12$ was performed by Phoenix (Hannover, Germany). The technique revealed the fracture pattern induced around the central hole (Fig. 3, left pictures). The cross sections show cracks mainly along the bedding planes (indicated by the white lines). The bedding planes split and buckle into the hole, inducing the rotation of fragments and slab-like breakouts in two regions that extend from the borehole in the direction normal to the bedding. The slab thickness is regular, but seems to increase away from the borehole. The width of the damaged region is similar to the diameter of the borehole. In the axial direction, the fractures constitute a connected network (Fig. 3, lower left).

To confirm the fracture pattern observed in the CT scans, the sample was impregnated with a mixture of Araldite and Laromin and then sawed into pieces (Fig. 3, right pictures). The bedding controlled excavation damaged zone is clearly discernible in sections normal to the hole axis. The cut along a diametral plane confirms also the axial connectivity of the induced fractures (close-up view in the lower right picture).

In parallel to the X-ray scans, permeability measurements were carried out under radial convergent flows before and after the mechanical unloading. An increase in hydraulic conductivity of about $40 \%$ (from $4.9 \pm 0.3 \times$ $10^{-13}$ to $6.8 \pm 0.5 \times 10^{-13} \mathrm{~m} / \mathrm{s}$ ) was measured, suggesting the development of a damaged zone around the central hole. As this measurement is an average value for the whole specimen, it is important to bear in mind that it is not representative of the increase in permeability in the damaged zone only. It is expected to be much more significant (by orders of magnitude), not only in the radial direction,
Fig. 2 Medium resolution X-ray Computed Tomography (XRCT) scans of the hollow cylinder specimen $\mathrm{N}^{\circ} 12$ prepared in an Opalinus Clay drill core parallel to the bedding planes. The upper scans were performed through the testing cell before (left) and after (right) the mechanical unloading. The lower images are scans 170 days (left) and 220 days (right) after the removal of the sample from the testing cell. Images courtesy of Lausanne Cantonal Hospital (CHUV)
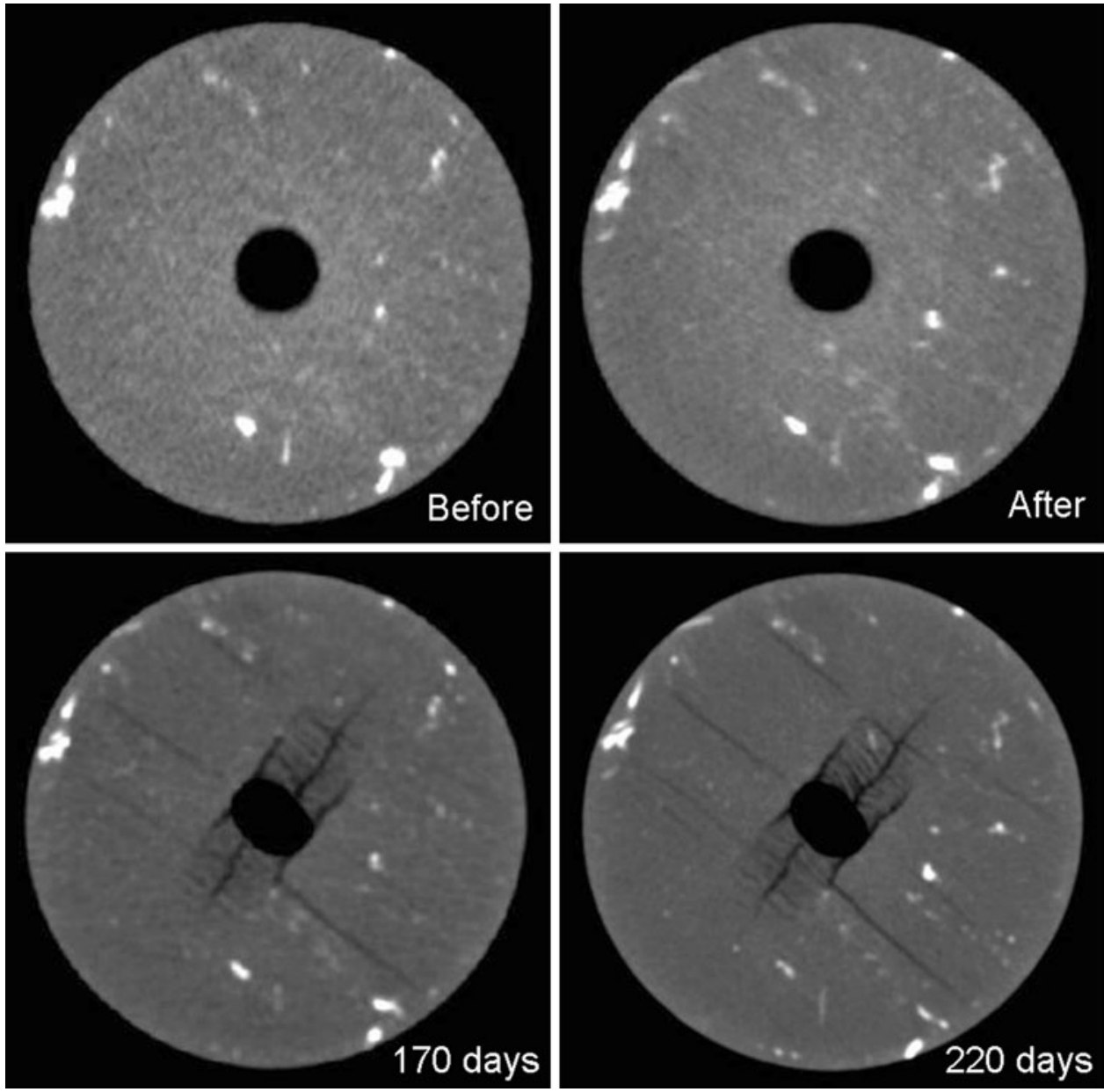
Fig. 3 High resolution XRCT scan of the central part of the Opalinus Clay hollow cylinder specimen $\mathrm{N}^{\circ} 12$ cored parallel to the bedding planes (left pictures, courtesy of Phoenix, Hannover). Pictures of the sample after its impregnation with resin and saw cutting: general view (upper right) and close-up views in a plane normal to the hole axis (middle right) and a diametral plane (lower right). Beddingcontrolled fracture pattern induced by the mechanical unloading
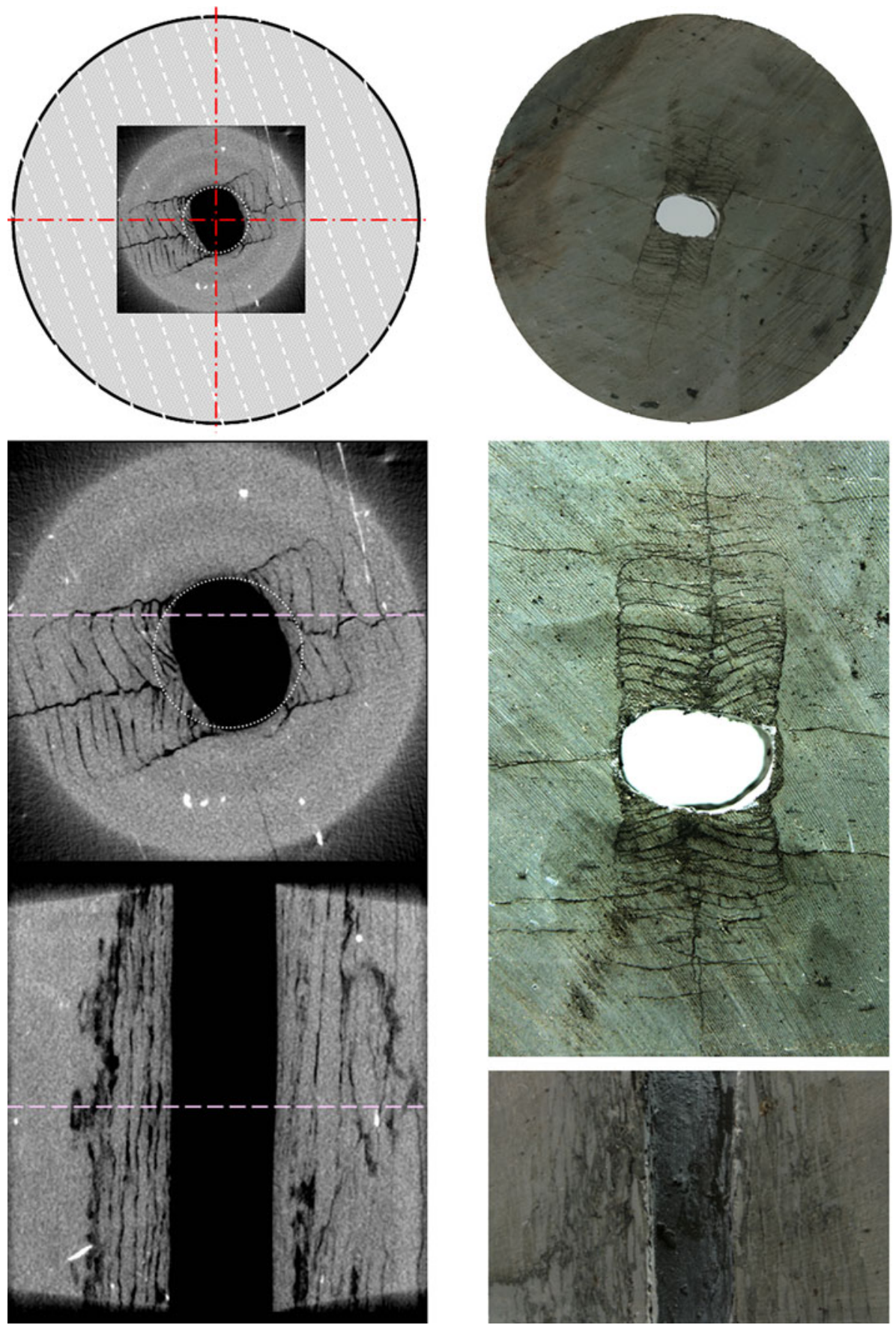

but rather in the axial direction due to the observed connectivity of fractures.

Putting together all the observations from the mediumand high-resolution XRCT scans, the visual inspection and the permeability measurements, it comes out that an "excavation" damaged zone was most probably induced by the mechanical unloading in the testing cell, but that the opening of fissures and the progress of the damaged zone further inside the clay took probably place when releasing the pressures before the dismantling of the testing cell and/ or after the test. The evolution of the damaged zone observed in the lower images of Fig. 2 may result from pore water pressures redistribution and/or desiccation when the sample was let to dry at room atmosphere after its removal from the testing cell, and this despite the resin impregnation.

A second test on an Opalinus Clay sample $\left(\mathrm{N}^{\circ} 2 / 5\right)$ cored parallel to the bedding planes was performed according to the testing procedure presented in Sect. 2.1. Tomography scans and permeability measurements were performed 
Fig. 4 Medium resolution XRCT scans of the Opalinus Clay sample $\mathrm{N}^{\circ} 2 / 5$ cored parallel to the bedding planes, before (left) and after (right) mechanical unloading. When looking carefully (arrows), slightly darker (i.e. less dense) zones can be noticed close to the hole wall in the direction normal to the bedding (white dashed lines). Images courtesy of Lausanne Cantonal Hospital (CHUV)
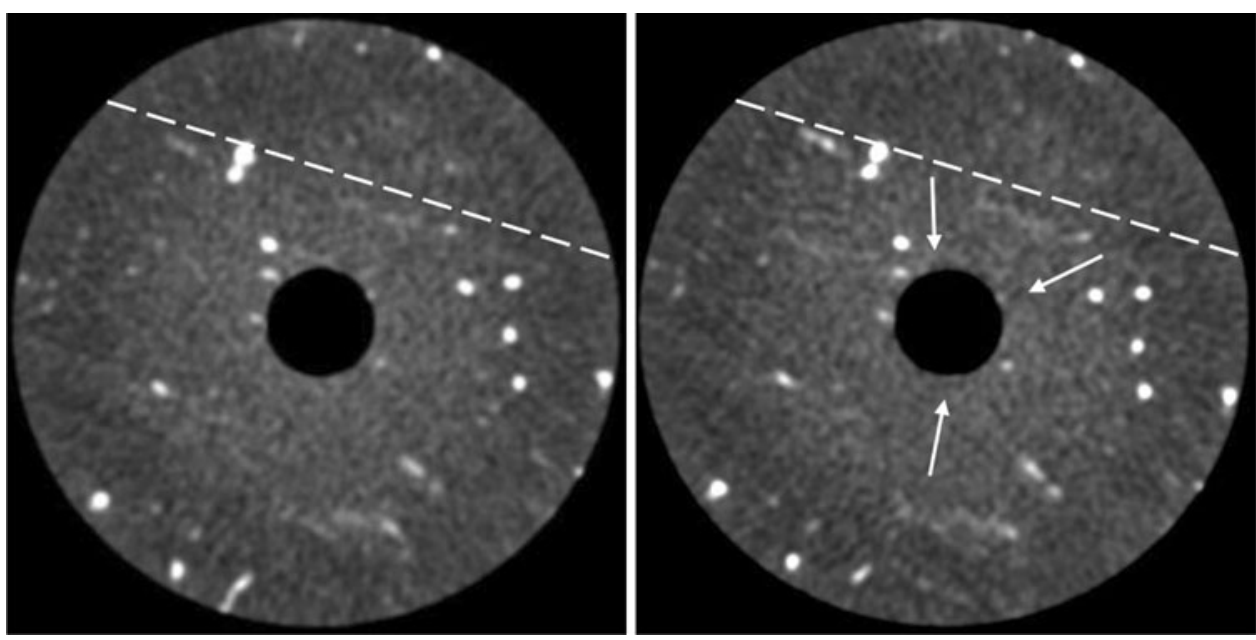

during the experiment, before and after the mechanical unloading.

The resolution of the X-ray tomography scans performed at Lausanne Cantonal Hospital is unfortunately too low to reveal fractures. Only a slight change in density can be noted when carefully comparing the images. Figure 4 illustrates for example the same CT slice of the $\mathrm{N}^{\circ} 2 / 5$ sample before and after mechanical unloading. Less dense zones (i.e. the slightly darker grey zones pointed by the arrows in Fig. 4) are barely discernible near the hole wall in the direction perpendicular to the bedding planes. A visual inspection of the sample after the test allowed distinguishing some early stage features of the fracture pattern observed in the first experiment, but with a much lessdeveloped failure mechanism (Fig. 5).

After the recovery of the mean in situ stress conditions, hydraulic conductivity values of $8.2 \pm 0.4 \times 10^{-13}$ to $1.1 \pm 0.02 \times 10^{-12} \mathrm{~m} / \mathrm{s}$ were measured, which is a bit higher than usual values on virgin clay. A small increase in flow of about $40 \%$ was observed after the mechanical unloading, up to a hydraulic conductivity value of $1.5 \pm 0.02 \times 10^{-12} \mathrm{~m} / \mathrm{s}$.

\subsection{Samples Cored Perpendicular to Bedding}

An experiment was carried out on an Opalinus Clay specimen $\left(\mathrm{N}^{\circ} \mathrm{C}\right)$ oriented perpendicular to the bedding planes. The preparation of samples in that direction proved to be extremely delicate. Although it was carefully performed, cracks sub-parallel to the bedding planes opened (Fig. 6 left). One crack located near the middle of the sample appeared to be more important, which was afterwards confirmed in the XRCT images (Fig. 6 middle and right). The test was nevertheless performed according to the stages schematically presented in Fig. 1.

Neither the comparison of the (medium resolution) XRCT scans performed before and after the mechanical

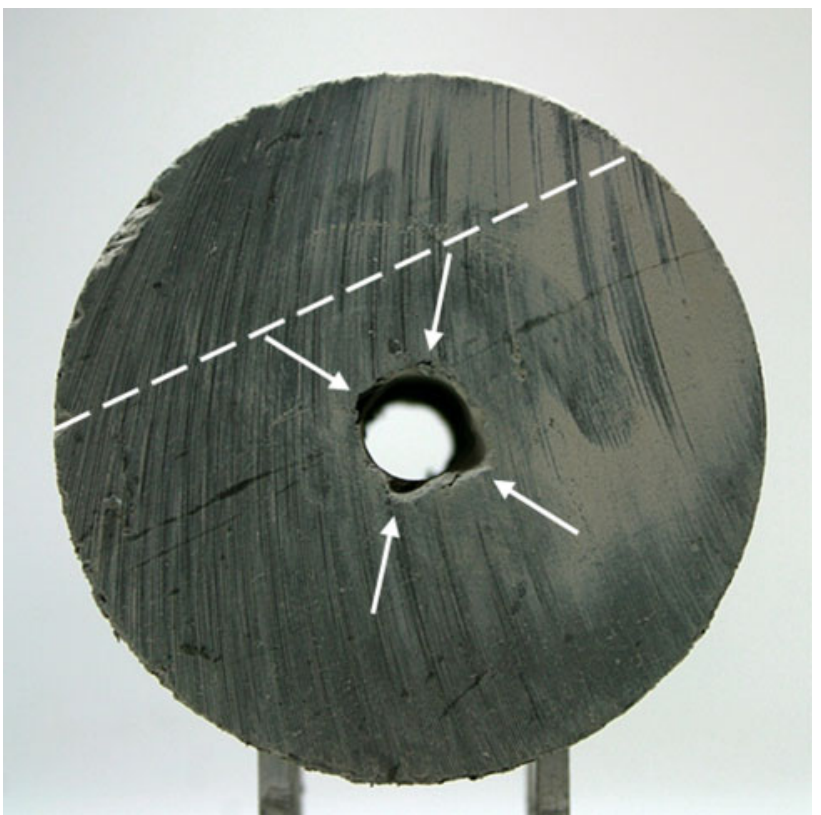

Fig. 5 Picture of the Opalinus Clay sample $N^{\circ} 2 / 5$ cored parallel to the bedding planes (white dashed line) after its removal from the testing cell and saw cutting. Early stage features of failure indicated by the arrows

unloading nor the visual inspection of the sample after its removal from the cell did point out a change in the sample, i.e. no oval-shaped deformation of the central hole, no breakout patterns and no change in density close to the hole, contrary to what was noticed for samples cored parallel to bedding. A close-up look at the CT slices near the crack sub-parallel to bedding located in the middle of the sample allowed, however, to observe some density changes related to the mechanical unloading (Fig. 7). They are possibly induced by an opening of some zones and closure of others, but as well by the presence of water along preferential flow paths. 

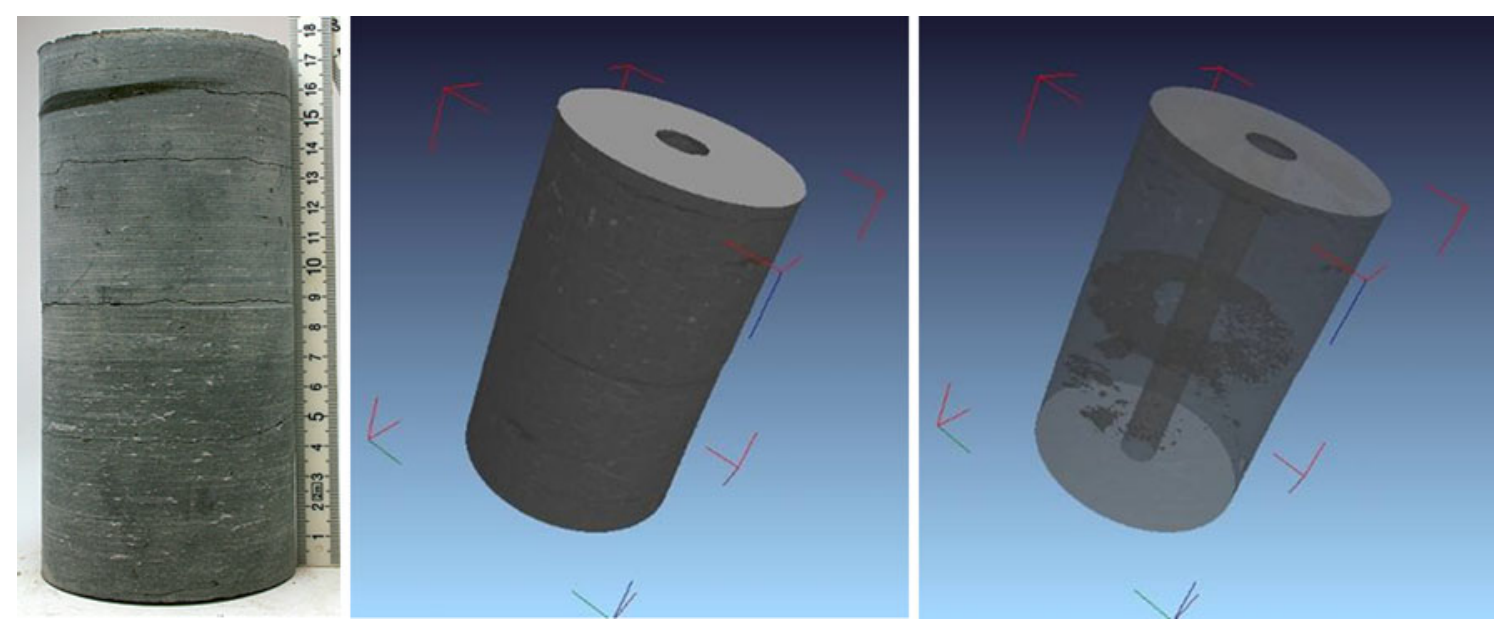

Fig. 6 Picture of the Opalinus Clay sample $\mathrm{N}^{\circ} \mathrm{C}$ after preparation (left) and medium resolution XRCT image stacks of the sample in the cell after mechanical unloading (middle and right) represented with

Precisely, as regards the hydraulic conductivity measurements, average values for the whole specimen ranged between $1.3 \times 10^{-11}$ and $5.8 \times 10^{-11} \mathrm{~m} / \mathrm{s}$ before the mechanical unloading, which are two orders of magnitude larger than values on virgin clay and certainly result from the preferential flow path through the cracks sub-parallel to the bedding planes. After the mechanical unloading, due to the clear connection between the outer and inner drains through the pre-existing cracks, it was hardly possible to impose a constant pressure difference and no permeability measurement could reasonably be achieved.

Another test on a sample $\left(\mathrm{N}^{\circ} \mathrm{D}\right)$ cored perpendicular to the bedding led to the same conclusions, i.e. neither an anisotropic deformation of the central hole nor breakout patterns was observed.

\section{In Situ Simulation Test}

In the framework of the TIMODAZ project NAGRA investigated the damage creation and self-sealing of boreholes in Opalinus Clay. As a part of this study the damaged zone of a borehole that had previously been stabilized by resin injection was excavated and studied in detail.

\subsection{Description of the Test}

The BSE-3 borehole under consideration follows the bedding strike of the Opalinus Clay has a diameter of $110 \mathrm{~mm}$ and is $12.1 \mathrm{~m}$ long. It had been drilled in 2003 for the earlier SELFRAC II experiment and had been equipped with a triple packer system (Bernier et al. 2006). The experiment demonstrated the self-sealing of the borehole EDZ around the packer located between 8.3 and $9.3 \mathrm{~m}$
VGS $^{\odot}$. The pre-existing crack near the middle of the sample is well discernible. It is parallel to the bedding planes. Scans courtesy of Lausanne Cantonal Hospital (CHUV)

from the wall of the adjacent gallery. During the test, the dilatometer pressure had been increased stepwise to 5.0 MPa. After the test completion, the packer system was removed in May 2007. After injection of dyed resin 3 weeks later, the borehole was then overcored in October 2007. The cores retrieved from the tested sections between 7.8 and $10.8 \mathrm{~m}$ were cut at 9 locations perpendicular to the overcore axis. Figure 8 shows the location of the slices along the overcore. The overcoring successfully maintained the orientation of the original borehole leading to an almost perfectly centralized position of the original borehole in the overcore up to the maximum depth. The mapping of geological structure on the core material of the original borehole and the overcore was done on photographs taken under UV light. The mapping revealed no abnormal tectonic features e.g. faults or fracture zones.

\subsection{Borehole Damage Zone Parallel to Bedding}

Two representative slices of the overcore have been selected to describe and discuss typical structural features in the borehole damage zone (BDZ). The upper one of these sections (at $7.92 \mathrm{~m}$ depth) is located in one of the test intervals that were not supported by the probe on the inside. The lower one of the two sections situated at $8.59 \mathrm{~m}$ was continuously supported by the dilatometer probe and loaded with pressures between 1 and $5 \mathrm{MPa}$ during the 3 years of the SELFRAC II experiment. However, both sections were unsupported for about 3 weeks between the retrieval of the probe and the resin injection.

The structure of the two BDZ sections from the dilatometer and the test interval is similar (Fig. 9). The elliptical opening in the centre of the sections represents the original borehole. It results from a larger convergence in 
Fig. 7 Medium resolution $\mathrm{X}$-ray CT images of the Opalinus Clay sample $\mathrm{N}{ }^{\circ} \mathrm{C}$ before (left) and after (right) mechanical unloading. The represented slice is crossing the crack that is visible near the middle of the sample in Fig. 6. The black areas are zones of the crack that are opened. Scans courtesy of Lausanne Cantonal Hospital (CHUV)
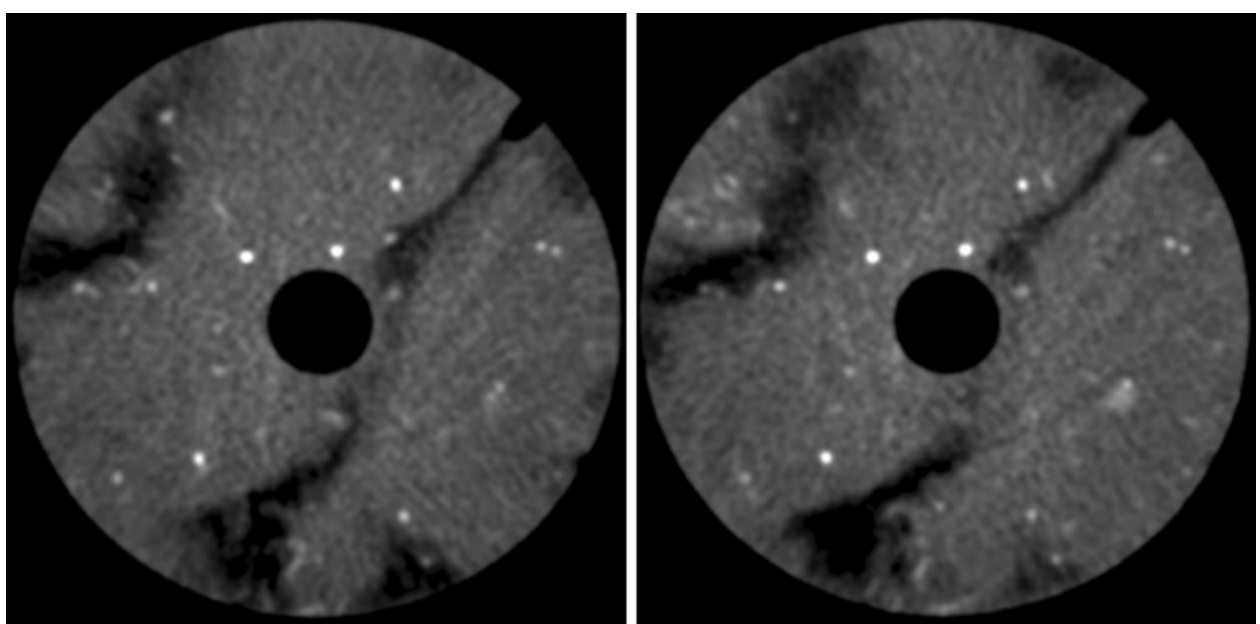

the direction normal to bedding than in the direction parallel to bedding (indicated by $S_{0}$ in Fig. 9).

The fractures that constitute the BDZ are concentrated in two regions that extend from the borehole in the directions normal to bedding. Extending beyond the limits of the overcore this central zone of the BDZ is larger than 1 borehole diameter. Its boundaries generally converge away from the borehole resulting in an almond shape with the borehole in the centre. In detail, the outer limits of this central region are curved and tend to rotate out of the bedding normal into a subvertical orientation.

Three different sets of fractures can be identified in the borehole damage zone (Bardertscher et al. 2008):

- F1 bedding parallel cracks with relatively smooth and long traces. They are distinctly denser inside the strongly deformed region.
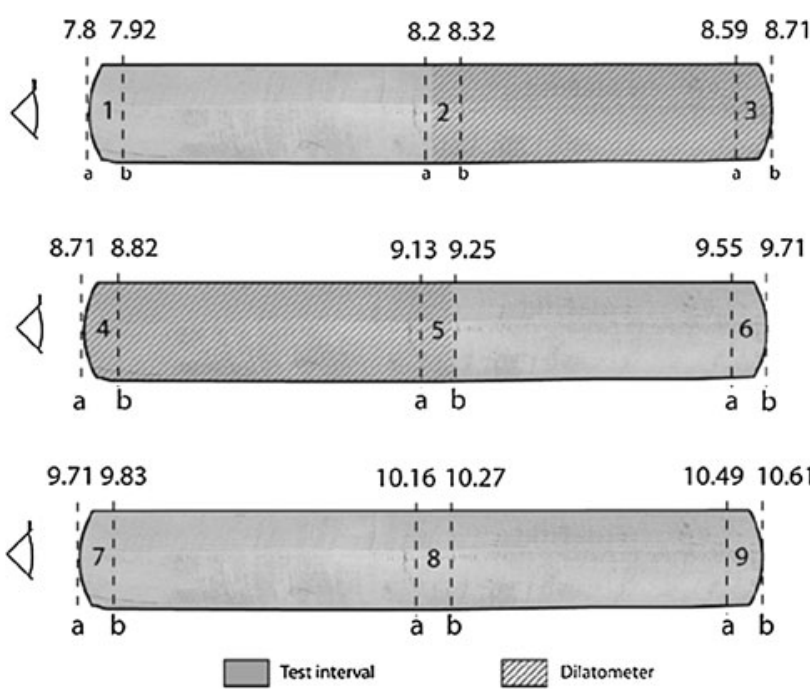

Fig. 8 Location of the sections in the overcore retrieved from the borehole BSE-3. The previous position of the loading element (dilatometer) is marked
- F2 cracks crosscutting the bedding at high angles. They consist of relatively short segments with irregular traces and link up to form the limits of the strongly deformed regions.

- F3 cracks at moderate angles $\left(30^{\circ}-45^{\circ}\right)$ to the bedding planes and located in the centre of the strongly deformed region. Close to the borehole, reverse motion sense indicating contraction parallel to the bedding planes is visible.

The fracture networks outside and inside the strongly deformed region differ significantly. Outside resin impregnations are found only on a few bedding planes ( $\mathrm{F} 1$ cracks). The spacing of the impregnated bedding planes appears to be quite regular. Inside the strongly deformed region, the rock is largely fractured into isolated fragments. They share a characteristic elongated cross section, thickness and length, and are bounded by failed bedding planes (F1). Individual bedding packets are cut in the centre of the deformed region by a F3 fracture. The fragments are rotated towards the centre and the amount of rotation decreases away from the original borehole.

The limits of the strongly deformed regions are formed by a series of short "en echelon" F2 cracks (see the boundary in red square in Fig. 9). These cracks are curved and bent towards the centre of the borehole. The cracks are located at the outer end of the rock fragments in the deformed zone. They allow the rotation of these platelets towards the borehole centre. The outer limit of the deformed zone is thus a complex structure formed by a number of individual F2 cracks. The limiting fracture array of the central zone apparently advances stepwise away from the borehole as the platy bedding fragments break along the F3 cracks in the centre, rotate and bend into the cavity.

A comparison of photographs from adjacent sections of the overcore shows that the overall fragment pattern and consequently also the surrounding fracture pattern can be 
(a)

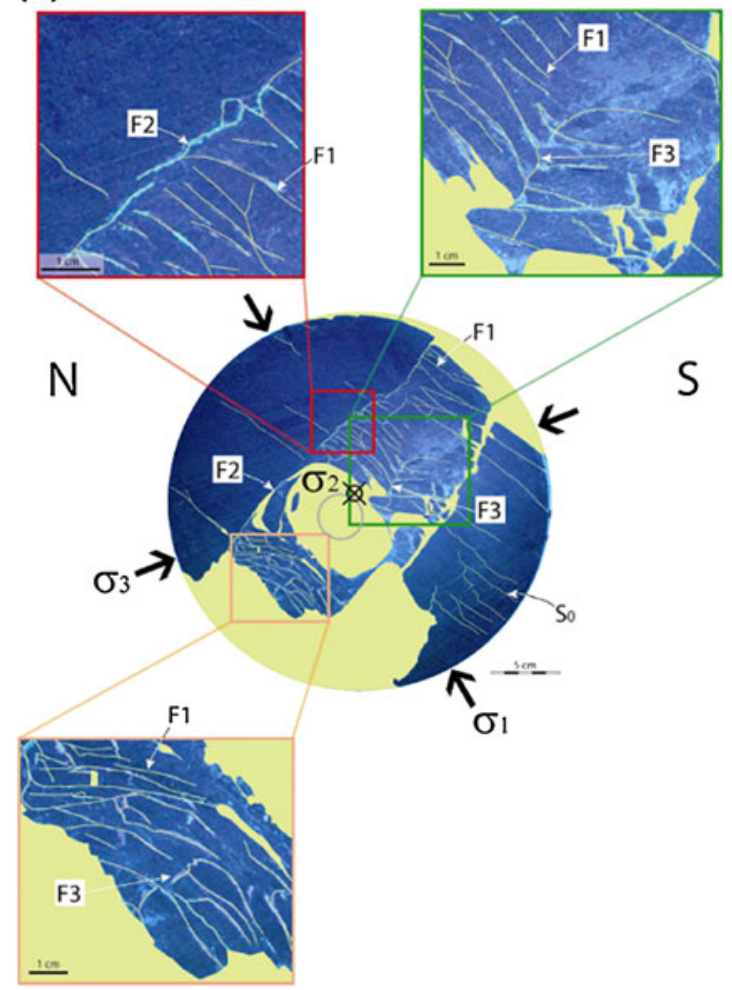

Fig. 9 Vertical sections of the overcore at depths of $7.92 \mathrm{~m}($ left $)$ and $8.59 \mathrm{~m}(r i g h t)$ with details of the failed regions. The original borehole is subhorizontal and represented by the oval shaped opening in the

traced between adjacent overcore sections. The maximum length of individual fragments corresponds to 4 diameters of the original borehole.

\subsection{Interpretation: Collapse Mechanisms of the BDZ}

The observed collapse of the borehole took place after the removal of the packer system. Otherwise the debris in the test interval would have been removed during this process. The overcore sections from the dilatometer and test intervals are indistinguishable. This indicates that the fracture pattern as developed during the late-stage collapse is also unrelated to the cyclic loading of the test and packer intervals by different water pressures and packer pressures, respectively.

Failure of the borehole after the removal of the test probe implies that the processes involved can be interpreted in the $2 \mathrm{D}$ sections. This is underlined by the similarity of adjacent cross sections. Observations in sections that are $250 \mathrm{~mm}$ apart (corresponding to 2 diameters of the original borehole) allow identifying the same fragment associations and fracture patterns. Therefore, 3D processes as described by Blümling et al. (2007) for the structures observed in boreholes in Boom Clay and clearly related to (b)

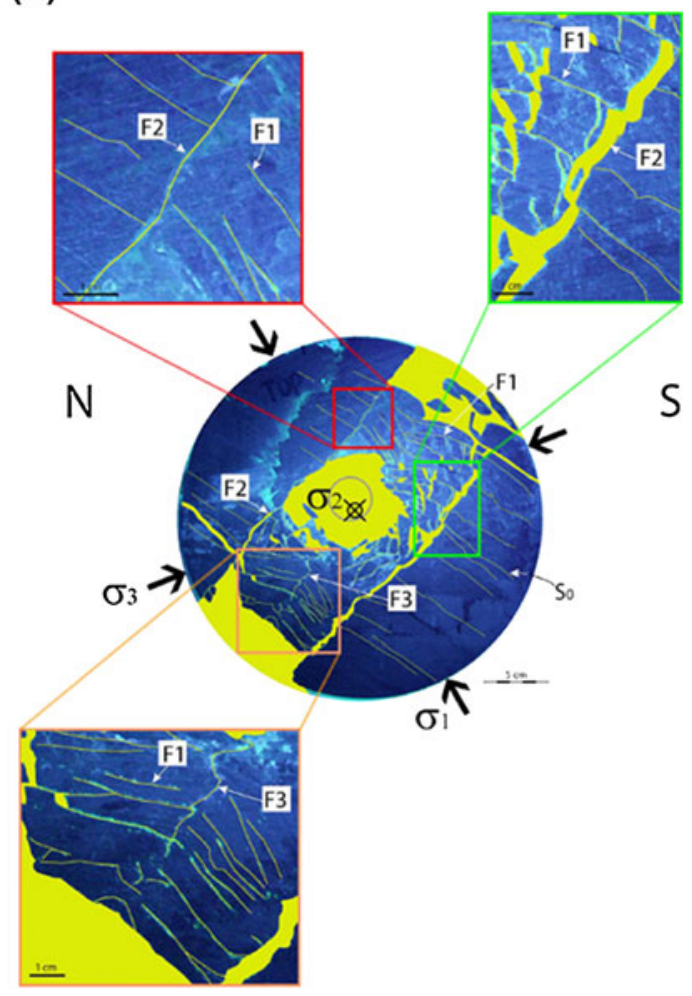

centre of each section. The bedding dips to the right. Original figure from Bardertscher et al. (2008) (color figure online)

the advancing drill bit are not relevant for the structures observed in the BDZ considered here.

The initiation and location of the late stage collapse structures are mainly controlled by the bedding anisotropy and the presence and orientation of the borehole itself. The observed fragmentation makes use of the weak bedding planes. The platelet contours are to the largest extent formed by bedding planes of the Opalinus Clay.

The influence of the principal stress directions is also reflected in detail in the observed fracture pattern. The F3 fractures that split the bedding fragments near the centre of the deformed region show consistently asymmetric arrangement with respect to the bedding plane normal. In the upper deformed region, the F3 cracks in the lowermost fragments always start on the right side of the borehole and then continuously move to the left in the higher segments. In the lower deformed region, the F3 cracks start at the very left and then move over to the right. Reassembling of the fragments shows that in both regions the F3 cracks have formed in a subvertical position and lead to shear failure of the fragment involved. Stress directions thus interact with the bedding planes in the fragmentation of the rock around the borehole. 
From the description of the fracture patterns and knowledge about the stress state the evolution of the BDZ collapse can be summarized as follows:

1. Excessive shear loading along the bedding planes in the tangential orientations to the borehole leads to shear failure initiation. The shear failure has a subvertical orientation (subparallel to the local maximum stress) and forms an acute angle with the bedding.

2. The shear fracture curves into a bedding parallel orientation and forms a first detached segment that starts to move along the bedding plane and the shear fracture and thus rotates into the existing borehole.

3. As the shearing motion along the shear fracture progresses the stresses are redistributed away from the failed bedding fragment on the intact rock further from the borehole. When the strength of the next flake is exceeded a second fracture is formed at low angle to the bedding, curves into a bedding plane parallel orientation and the next fragment starts to move and rotate.

4. The rotation of the fragments leads to cracking where rotation is inhibited by confining stresses farther away from the borehole.

The identification of the failure mechanisms and the unravelling of the sequence of events during collapse allow developing a conceptual model for the damage around small circular excavations parallel to the bedding of the strongly anisotropic Opalinus Clay. Conceptual models for the BDZ - during testing and after removal of the supporting test system installations-are depicted in Fig. 10.

During excavation, the initial damage, including failure of a few bedding planes does not affect the overall borehole stability. It has been recognised that Opalinus Clay becomes stronger by drying. Thus, the air flushed drilling may substantially contribute to the borehole stability. The insertion of the triple packer test system stabilizes the packer sections and the adjacent test intervals, the low clearance in the test intervals may have some supporting effect.

After removal of the test system-the SELFRAC dilatometer probe- the borehole collapses. The removal of the test system completely unloads the borehole wall. This reduces the friction on the shear fractures and the bedding planes (F3 and F1 cracks) and thus allows shear displacements and rotations of the fragments into the cavity. In addition, the loaded and partly damaged bedding planes are now resaturated. This allows free swelling to take place which forces apart the damaged bedding planes and thus further reduces the stability. Long axial fragments are formed that are surrounded by long axial cracks. Most of them follow the bedding planes. The rotation and convergence of fragments in the borehole vicinity unload deeper bedding planes and allow their buckling and failure. This process affects progressively deeper regions and the borehole collapses completely.

\section{Discussion}

\subsection{Laboratory and In Situ Results}

The hollow cylinder simulation experiments have revealed that samples cored in directions parallel and perpendicular to the bedding planes behave very differently. In the former case, cracks sub-parallel to the bedding planes open and lead to a buckling failure in two regions that extend from the borehole in the direction normal to bedding. An oval shape deformation of the central hole is as well noticed. On
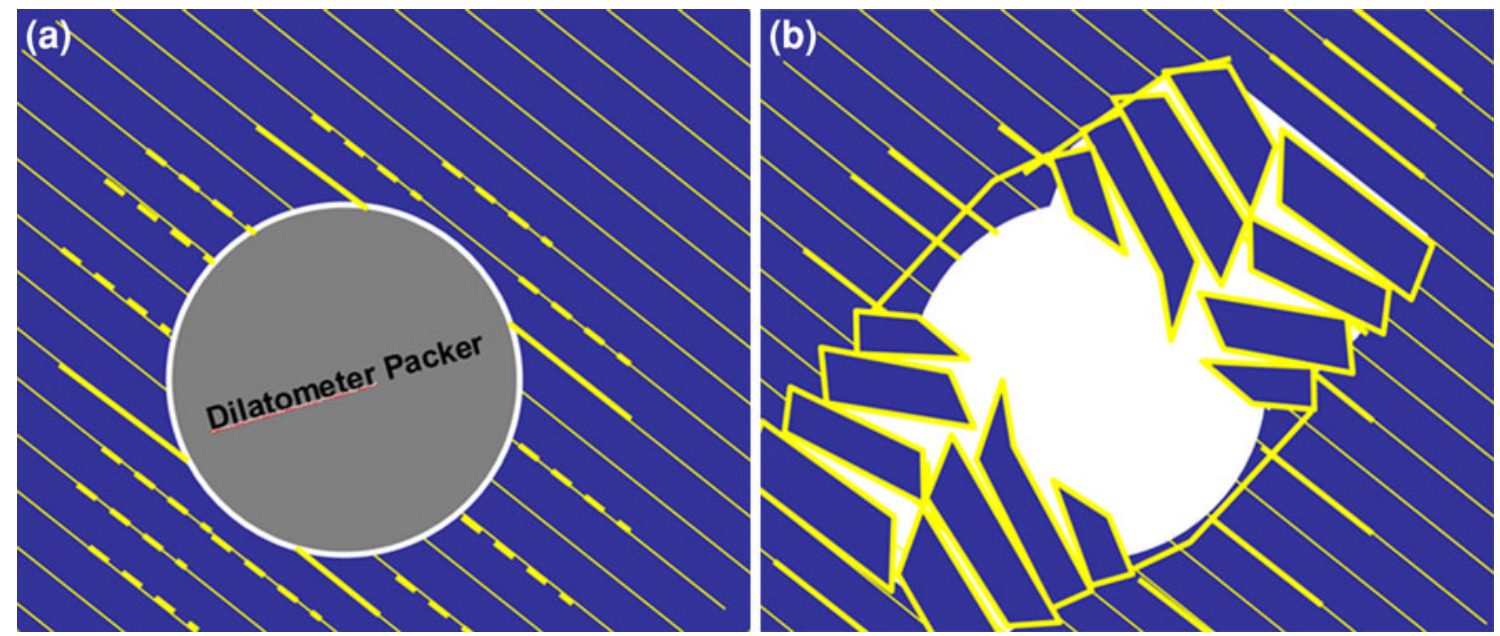

Fig. $10 \mathrm{BDZ}$ status during long-term hydrotesting (left) and after collapse (right) 
the other hand, in the specimens cored perpendicular to bedding, neither failure patterns nor anisotropic response are observed (visually and at the medical scanner resolution). It is therefore apparent that the "excavation" damaged zone induced around the central hole is controlled by the orientation of the sample with respect to the bedding.

The in situ experiment at Mont Terri consisting in the overcoring of a resin-injected borehole that follows the bedding strike of the Opalinus Clay has shown a bedding controlled "excavation" damaged zone consistent with the fracture pattern observed in the hollow cylinder tests on samples cored parallel to bedding. Both laboratory and in situ simulation tests thus underline the significance of the preexisting planes of weakness (bedding planes) in Opalinus Clay and the need for a correct consideration of the related mechanical anisotropy. Such similarities of the observations contribute to increase confidence in the understanding of the on-going processes and in their modelling.

\subsection{In Situ Observations}

Distinct fracture patterns are observed around boreholes and galleries at the Mont Terri Underground Laboratory, depending on their orientation with respect to bedding and to the in situ stress field (Martin and Lanyon 2003; Blümling et al. 2007; Bossart et al. 2002). Bedding plane failure is found particularly prominent when the opening axis is oriented parallel to bedding. Fracture patterns around boreholes are rather consistent with the geometry and extent of the damaged zone observed in the laboratory and in situ simulation tests (Figs. 3,9). In these conditions with no support in boreholes or very little support in the hollow cylinder tests (i.e. $100 \mathrm{kPa}$ radial effective stress applied on the central hole wall), the deformation can proceed and the fragmentation can progress away further into the rock. Such a progressive breakout evolution in a borehole drilled parallel to the bedding strike is for example observed in Fig. 11 by comparing the screenshots of borehole videos taken 3 months apart (Seeska et al., in preparation 2013). In extreme cases, progressive breakout can even lead to collapses, as the instability observed on a larger scale above a horseshoe type gallery at Mont Terri oriented parallel to the bedding planes (Blümling et al. 2007).

Observations of borehole collapse structures have been used previously to develop conceptual models for the EDZ around larger excavations following bedding (Vietor et al. 2006). However, the transferability of BDZ observations to the structure and organisation of the EDZ of galleries and tunnels parallel to bedding strike is subject to limitations concerning scale dependence of processes and the differences in excavation techniques used for boreholes and galleries.
Boreholes are drilled with double core barrel. Drilling is very fast with respect to the size of the excavation $(10 \mathrm{D} / \mathrm{h})$ and also leads to a perfect circular opening that is created in a full face simultaneous unloading at the drill bit front. In contrast, the excavation of galleries with a road header or pneumatic hammer is much slower $(0.05 \mathrm{D} / \mathrm{h})$ and leads to a more irregular evolution of the excavation geometry. This in turn will result in irregular and non-systematic stress paths around the excavation face.

The fast unloading of the rock face during drilling with continuously repeated stress paths around the advancing drill bit therefore favours an axially continuous distribution of incipient damage in the BDZ. In contrast, the irregular and geometrically imperfect excavation of a tunnel using a point excavation method leads to an irregular stress path around the advancing tunnel face. Hence, the conditions for a long axially connected fracture network are likely to be less favourable in tunnel excavations than in borehole drilling.

More, the differences in incipient excavation damage will be amplified by the daily and weekly interruptions of the tunnel excavations and the application of support measures. Other differences could also arise from the distribution of pre-existing features in the rock. As the average spacing of tectonically weakened structures subparallel to bedding is $0.5-1 \mathrm{~m}$ in Opalinus Clay, drill holes parallel to bedding with a diameter of $0.1 \mathrm{~m}$ will most likely miss tectonic faults. In contrast, tunnels with a diameter of $2.5 \mathrm{~m}$ or more will intersect one or more of those planes.

Further differences in the fracture network evolution of boreholes and tunnels will result from the different pore water pressure evolution in the host rock. In the SELFRAC II experiment, the re-saturation of the BSE-3 borehole was done artificially after the stabilisation of the contour by packer systems and took a few minutes. Hence, the borehole contour was always supported during the re-saturation. The effect of the re-saturated bedding planes became only visible in the borehole test after removal of the dilatometer probe. The latter operation allowed free swelling to take place along the damaged bedding planes and is a likely reason for an accelerated collapse. In contrast, due to the extremely low permeability of the rock mass and because the time for pore pressure re-equilibrium is proportional to the square of the excavation size, the pore water pressures around galleries and tunnels will evolve for several decades to a few centuries and the swelling rate of the Opalinus Clay in the tunnel EDZ will be limited by the slow water flow from the far field. Moreover, the tunnels will be backfilled by bentonite which will provide normal stresses onto most of the tunnel contour. Hence, the additional damage in the EDZ by free swelling of the Opalinus Clay will be quite limited. 


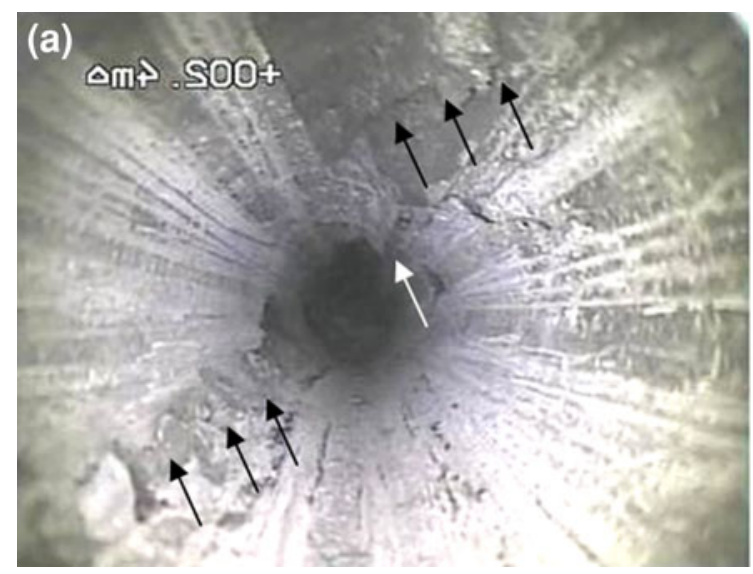

Fig. 11 Screenshots of borehole videos showing the progressive evolution of damage in a horizontal borehole following the bedding (Seeska et al., in preparation 2013). Bedding planes dip $\sim 45^{\circ}$ to the right. The images were flipped to allow comparison with Fig. 10. Right image taken 3 months after left image at different depth

\subsection{Implications for the Geological Disposal of Radioactive Waste}

As repository tunnels will follow the bedding in the Opalinus Clay formation, one could have some concern about the development of an extensive EDZ above and below the openings. However, the buckling mechanism and the progressive breakout evolution observed in the simulation experiments and around openings in situ are related to conditions with no or very little support. They may be avoided by installing adequate support measures right at the excavation face. Consequently, only a rather limited progress of the excavation damaged zone is to be expected after construction for repository tunnels which will be properly supported during their 2 years operation period and quickly backfilled after the emplacement of the radioactive waste canisters.

Later, after saturation of the backfill, the repository tunnel EDZ will be loaded by the swelling pressure of the backfill material. This concept has been investigated in the SELFRAC II borehole test with the help of the dilatometer probe (Bernier et al. 2006). The test demonstrated sealing within years to almost undisturbed transmissivities once the backfill material has developed the full swelling pressure.

In conclusion, the analysis of the hollow cylinder experiments and the collapsed borehole BSE-3 illustrates the failure mechanisms in the highly anisotropic Opalinus Clay around excavations parallel to strike. They also hint towards the possible geometries for fracture networks around larger scale bedding parallel emplacement tunnels and galleries. However, the observed axially continuous BDZ fracture network implying a high axial connectivity cannot be directly transferred to full scale excavations for

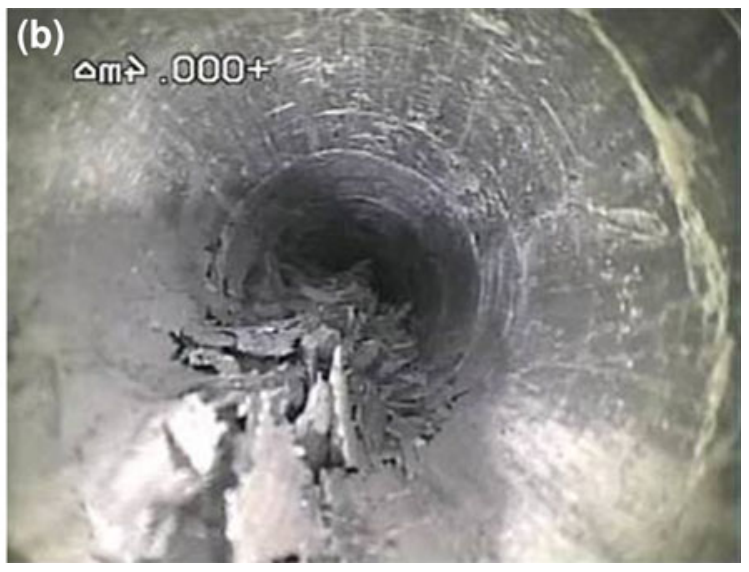

positions. Left shearing along bedding (black arrows) and incipient buckling in the background (white arrow). Right fragment rotation in deeper regions pushes up the borehole contour to form a triangular structure; about a third to a half of the borehole circumference is affected by the failure

the following reasons: (1) the tunnel and gallery EDZ that has to be included into the long-term performance assessment will not develop to complete collapse. (2) Support measures may be used in the operational phase to reduce the connectivity of the fracture network in the case of the emplacement tunnels. (3) The backfill of the tunnels will not allow their collapse. Unlike the boreholes investigated here, the damage around tunnels and galleries parallel to bedding will most likely have a more irregular fracture pattern with a lower axial connectivity. More, due to the backfilling of the galleries, the overall relative convergence will be much lower than in the hollow cylinder experiments and the BSE-3 borehole.

Further investigations are necessary for an adequate design of the support measures to be taken during the construction of repository tunnels and of their backfill to control the progress of damage into the rock mass and to prevent any breakout occurrence. They could among others rely on thick-walled hollow cylinder simulation experiments with various outer and inner confining pressures aiming at mimicking different disposal depths and support/ backfilling concepts.

\subsection{Differences with Boom Clay}

Opalinus Clay, as Boom Clay and any bedded sediments, exhibits an anisotropic, mainly transversely isotropic behaviour. Therefore, although the mechanical loading applied in hollow cylinder tests is isotropic, when specimens are cored parallel to the bedding planes, it is expected to observe an overall oval-shaped deformation of the central hole with principal axes about parallel and orthogonal to the bedding. This is actually the case, but the ovalisation is occurring in reverse directions in the two clays... related 
to the fact that the damaged zone is developing in reverse directions too. It seems to have an eye-shape in Boom Clay with a major axis in the bedding planes direction (Labiouse et al. 2013), whereas it extends in the direction normal to bedding in Opalinus Clay and is limited to the width of the hole. This rather unexpected observation is most probably related to different modes of failure in the two clays: shear failure prevails along conjugated planes in the plastic Boom Clay, while bedding plane splitting and buckling occur in the indurated Opalinus Clay.

In situ, the observed dissimilarities around URL galleries at Mol and Mont Terri (e.g. fracture pattern developing in reverse directions) could actually be related to differences in overconsolidation ratios of the clayey formations and/or in in situ stresses at the Underground Research Laboratories sites. As a matter of fact, although the Callovo-Oxfordian Clay is hard and indurated like Opalinus Clay, a fracture pattern similar to the observations made at Mol in Boom Clay (i.e. conjugated shear planes) was noticed in some places at Bure URL (Wileveau and Bernier 2008). Accordingly, conjugated shear planes could possibly be observed around galleries at greater depth in Opalinus Clay.

\subsection{Similarities with Well Stability Problems in Shales}

The bedding-controlled failure patterns observed in the reported experiments and around openings at Mont Terri URL as well as their dependence on the orientation of the cavities with respect to the bedding planes are not necessarily novel. Similar failure mechanisms are indeed documented in petroleum engineering researches related to wellbore stability problems in materials with distinct bedding. For example, field experience of wells in Kimmeridgian shale of the Oseberg zone in the Norwegian North Sea did not indicate problems when the drilling was normal or inclined with respect to bedding (Økland and Cook 1998). On the other hand, severe stability problems were experienced when drilling parallel or close to parallel to bedding. Similarly, Brehm et al. (2006) describe borehole instabilities observed during drilling operations in weakly bedded rocks in the Gulf of Mexico. They are reported as almost non-existent when drilling at angles nearly perpendicular to the bedding planes, but more severe and anisotropic when drilling at low-angles-of-attack to bedding.

Similar observations were made in thick-walled hollow cylinder tests on samples of shales cored perpendicular and parallel to bedding. In particular, in the latter orientation, bedding planes were found to split and buckle into the hole, inducing significant breakouts in the direction normal to the bedding planes (Økland and Cook 1998). Swellinginduced damage experiments performed by Cook et al.
(1994) to study mud-shale interactions in wellbores also revealed an influence of the bedding plane orientation on the shale swelling, which might suggest that the instability mechanism and the related anisotropic damage zone could further develop after drilling.

\section{Conclusions}

Within the framework of the TIMODAZ project, the Rock Mechanics Laboratory of the EPFL and the Swiss National Cooperative for the Disposal of Radioactive Waste NAGRA performed laboratory and in situ experiments, respectively, to study the failure processes around tunnels in the indurated Opalinus Clay at Mont Terri, Switzerland.

Hollow cylinder simulation experiments with a mechanical unloading mimicking a gallery excavation were first performed on samples cored parallel to the bedding planes. XRCT scans of the samples as well as visual inspections after removal from the testing cell and resin impregnation revealed the development of a fracture pattern around the central hole. Cracks sub-parallel to the bedding planes open and lead to a buckling failure in two regions that extend from the borehole in the direction normal to bedding. The width of the damaged zone is similar to the borehole diameter. On the other hand, in experiments performed on specimens cored perpendicular to bedding, there was no indication of failure around the central hole and the response of the hollow cylinder sample was mainly isotropic.

The in situ investigation was performed in the Mont Terri Underground Rock Laboratory (URL) around a borehole that follows the bedding strike of the Opalinus Clay. After injection of the borehole with resin and overcoring, sections of the core were saw-cut to study the damage around the borehole. The geometry and extent of the fracture pattern have shown a striking similarity with the damaged zone observed around the central hole of the hollow cylinder tests on samples cored parallel to bedding.

Both laboratory and in situ experiments underline the significance of the pre-existing planes of weakness in Opalinus Clay and the importance of the mechanical anisotropy arising from this bedded microstructure. This conclusion of a bedding controlled "Excavation" Damaged Zone is consistent with the distinct fracture patterns observed at Mont Terri depending on the orientation of holes/galleries with respect to the bedding planes.

By comparing the laboratory experiments performed on Boom and Opalinus Clay samples cored parallel to the bedding planes, it has been pointed out that the deformation of the central hole and the development of the damaged zone are occurring in reverse directions. It has an eye-shape in Boom Clay with a major axis in the bedding 
planes direction whereas it extends in the direction normal to bedding in Opalinus Clay and is limited to the width of the hole. This difference in behaviour most probably results from different failure mechanisms: i.e. shear failure along conjugated planes in the plastic Boom Clay, but bedding plane splitting and buckling in the indurated Opalinus Clay.

Acknowledgments The TIMODAZ project is co-funded by the European Commission and performed as part of the sixth EURATOM Framework Programme for nuclear research and training activities (2002-2006) under contract FI6 W-CT-2007-036449. The Mont Terri URL is an international project of 14 partners from 7 countries and is lead by Director P. Bossart of the Federal Office for Topography, Swisstopo. The support of the Mont Terri staff under the supervision of the Project Manager C. Nussbaum is gratefully acknowledged. Further acknowledgements go to Laurent Gastaldo and Shuang You who contributed to the LMR-EPFL experiment and to Martine Bernasconi of the Department of Diagnostic and Interventional Radiology of the CHUV (Lausanne Cantonal Hospital) for the X-ray computed tomography scans of the hollow cylinders. Finally, the Authors are grateful to two anonymous reviewers, whose suggestions and comments helped to improve the quality of the paper.

\section{References}

Bardertscher N, Girardin C, Nussbaum C (2008) SE-H Experiment: EDZ structural analysis of resin impregnated sections from BSE3 overcore. Mont Terri Technical Note TN 2008-15, Saint Ursanne, Switzerland

Bernier F, Li XL, Bastiaens W, Ortiz L, Van Geet M, Wouters L, Frieg B, Blümling P, Desrues J, Viaggiani G, Coll C, Chanchole S, De Greef V, Hamza R, Malinsky L, Vervoort A, Vanbrabant Y, Debecker B, Verstraelen J, Govaerts A, Wevers M, Labiouse V, Escoffier S, Mathier J-F, Gastaldo L, Bühler C (2006) SELFRAC: Fractures and self-healing within the excavation disturbed zone in clays: Final technical report EUR 22585. Commission of the European Communities, Luxembourg

Blümling P, Bernier F, Lebon P, Martin CD (2007) The excavationdamaged zone in clay formations-time-dependent behaviour and influence on performance assessment. Phys Chem Earth 32(5-14):588-599

Bossart P, Meier PM, Moeri A, Trick T, Mayor J-C (2002) Geological and hydraulic characterisation of the excavation disturbed zone in the Opalinus Clay of the Mont Terri Rock Laboratory. Eng Geol 66:19-38
Brehm A, Ward C, Bradford D, Riddle G (2006) Optimizing a deepwater subsalt drilling program by evaluating anisotropic rock strength effects on wellbore stability and near-wellbore stress effects on the fracture gradient. In: Proceedings of IADC/ SPE Drilling Conference, Miami, Florida, USA, IADC/SPE 98227

Cook JM, Goldsmith G, Bailey L, Audibert A, Bieber M-T (1994) $\mathrm{X}$-ray tomographic study of the influence of bedding plane orientation on shale swelling. In: Proceedings of SPE/ISRM Eurock 1994, Delft, The Netherlands, pp 267-274

Labiouse V, Sauthier C, You S (2013) Hollow cylinder simulation experiments of galleries in Boom Clay formation. Rock Mech Rock Eng. doi:10.1007/s00603-012-0332-0 (this issue)

Martin CD, Lanyon GW (2003) Measurement of in situ stress in weak rocks at Mont Terri Rock Laboratory, Switzerland. Int J Rock Mech Min Sci 40:1077-1088

Nagra (2002) Projekt Opalinuston: Synthese der geowissenschaftlichen Untersuchungsergebnisse. Technischer Bericht 02-03. Nagra, Wettingen, Switzerland

Nagra (2008): Vorschlag geologischer Standortgebiete für das SMAund das HAA-Lager, Geologische Grundlagen. Technischer Bericht 08-04, Nagra, Wettingen, Switzerland

Økland D, Cook JM (1998) Bedding-related borehole instability in high-angle wells. In: Proceedings of SPE/ISRM Eurock 1998, Trondheim, Norway, pp 413-421

Popp T, Salzer K, Minkley W (2008) Influence of bedding planes to EDZ-evolution and the coupled HM properties of Opalinus Clay. Phys Chem Earth 33:374-387

Seeska R, Lux KH, Hesser JBB experiment: long term deformation behaviour of boreholes. Mont Terri Technical Note TN 2011-04, Saint Ursanne, Switzerland (in preparation)

Tsang C-F, Bernier F (2004) Definitions of excavation disturbed zone and excavation damaged zone. European Commission Report EUR 21028 EN, Luxembourg

Van Marcke P, Bastiaens W (2010) Excavation induced fractures in a plastic clay formation: observations at the HADES URF. J Struct Geol 32:1677-1684

Vietor T, Blümling P, Armand G (2006) Failure mechanisms of the Opalinus Clay around underground excavations. In: Proceedings of Eurock 2006, ISRM reg symp, Liège, Belgium, pp 479-484

Vietor T, Alheid HJ, Blümling P, Bossart P, Gibert D, Heusermann F, Nicollin S, Nussbaum C, Plischke I, Schuster K, Shin K, Spies T (2008) Rock mechanics experiments. In: Bossart, Thury (eds) Mont Terri Rock Laboratory Project, Programme 1996 to 2007 and Results. Reports of the Swiss Geological Survey 3, Wabern

Wileveau Y, Bernier F (2008) Similarities in the hydromechanical response of Callovo-Oxfordian clay and Boom Clay during gallery excavation. Phys Chem Earth 33:343-349 